ISSN: 0213-2060

DOI: https://doi.org/10.14201/shhme20183626181

\title{
EL ACCESO A LA CULTURA Y LA FORMACIÓN INTELECTUAL EN ANDALUCÍA DURANTE LA BAJA EDAD MEDIA
}

\author{
The Access to Culture and Education in Andalusia during the Late Middle Ages \\ Silvia María PÉREZ GONZÁLEZ \\ Área de Historia Medieval. Universidad Pablo de Olavide.Crta.Utrera, km 1.E-41013 SEVILLA. C. e.: spergon@upo.es \\ Juan Carlos ARBOLEDA GOLDARACENA \\ Área de Historia Medieval.Universidad Pablo de Olavide.Crta. Utrera, km 1.E-41013 SEVILLA. C. e.: jcarbgol@upo.es
}

Recibido: 2018-01-30

Revisado: 2018-04-05

Aceptado: 2018-10-29

RESUMEN: En el presente trabajo estudiamos el mundo de la cultura en Andalucía durante los últimos siglos de la Edad Media. Abordamos los distintos tipos de formación (universitaria, secundaria y primaria) con sus centros de estudio; el acceso a los libros y bibliotecas como motores privilegiados de la cultura; y la relación de la mujer con el mundo cultural.

Palabras clave: Cultura; Educación; Andalucía; Baja Edad Media; Universidades.

ABSTRACT: In this paper we study the cultural universe in Andalusia during the Late Middle Ages. We focus our attention on the different moments of education and their schools (Universities, secondary schools, elementary schools); the access to books and libraries as a main source for culture; and the link between women and culture.

Keywords: Culture; Education; Andalusia; Late Middle Ages; Universities.

SUMARIO: 1 La formación académica y sus centros. 1.1 Los estudios universitarios. 1.2 La enseñanza secundaria. 1.3 La enseñanza primaria. 2 Libros y bibliotecas. 3 Mujeres y cultura. 4 Conclusiones. 5 Referencias bibliográficas. 


\section{LA FORMACIÓN ACADÉMICA Y SUS CENTROS}

A finales del siglo xv y principios del xvi tuvo lugar una revolución educativa motivada por las necesidades administrativas y burocráticas de las nuevas monarquías. Con ella se buscaba dar respuesta a las diversas necesidades de los nuevos estados dentro de un capitalismo emergente. Por otro lado, el desarrollo urbano desde la Plena Edad Media no solo supuso una ampliación del mercado de trabajo, sino también la multiplicación de unas actividades profesionales que necesitaban una formación intelectual cada vez más completa. Los conocimientos técnicos, culturales y científicos se desarrollaron unidos a actividades prácticas con el objetivo de conservar y transmitir los contenidos propios de cada oficio ${ }^{1}$. Así nació una cultura urbana, con tendencia a la secularización, que hizo necesaria la implementación de nuevos instrumentos para la difusión de los conocimientos que esta sociedad requería, aunque controlados casi en su totalidad por la Iglesia. Ello dio lugar al desarrollo de nuevos centros de enseñanza perfectamente imbricados en el nuevo contexto social y radicados en las ciudades.

\subsection{Los estudios universitarios}

Si bien la fundación de la Universidad de Sevilla no tuvo lugar hasta 1505, ello no fue óbice para que en Andalucía hubiera personas con grados universitarios ${ }^{2}$ e, incluso, funcionaran algunas cátedras como precursoras del nacimiento de la propia Universidad $^{3}$. Para Sevilla conocemos la existencia de algunas cátedras de Derecho y Teología, cuyo lugar de impartición era la capilla del patio de los naranjos de la catedral. Los datos sobre la cátedra de Derecho no son muy determinantes, pues, salvo la autorización concedida a un bachiller en leyes por la Universidad de Salamanca para recibir en Sevilla la licencia y doctorado ${ }^{4}$, no contamos con más información.

La información sobre la cátedra de Teología es más concluyente, pues tenemos constancia de la existencia de un profesor de esta en 14245. La cátedra se localizaba en la capilla de San Miguel de la catedral hispalense, y se conocen los nombres de algunos de sus titulares, así como el ritual de toma de posesión del puesto ${ }^{6}$.

1 Caunedo del Potro, Betsabé y Córdoba de la Llave, Rafael. «Oficios urbanos y desarrollo de la ciencia y la técnica en la Baja Edad Media: la Corona de Castilla». Norba. Revista de Historia, 2004 , vol. 14 , p. 53.

2 Recordemos que los estudiantes de las universidades medievales podían obtener tres grados: el de bachiller, el de licenciado y el de doctor. Cada uno de estos niveles requería un tiempo concreto, así como unos estudios específicos (Le Goff, Jacques. Los intelectuales en la Edad Media. Barcelona: Gedisa, 2009, pp. 79-83).

3 Sánchez Herrero, José. De las primeras letras a la Universidad en la Sevilla de finales del siglo XV. Sevilla: Servicio de Publicaciones de la Universidad de Sevilla, 2010, p. 85.

4 Beltrán de Heredia, Vicente. Bulario de la Universidad de Salamanca. Salamanca: Universidad de Salamanca, 1966, vol. I, doc. n. ${ }^{\circ} 176$.

5 Ibidem, II, doc. n. ${ }^{\circ} 696$.

6 Rubio Merino, Pedro. Archivo de la Santa Metropolitana y Patriarcal Iglesia catedral de Sevilla. Inventario general. Madrid: Fundación Ramón Areces, 1987, Sección I: Secretaría 2. Libro de Actas Capitulares, 1478-1480, 15 de octubre de 1478 , fol. $34 \mathrm{v}$. 
EL ACCESO A LA CULTURA Y LA FORMACIÓN INTELECTUAL EN ANDALUCÍA DURANTE LA BAJA EDAD MEDIA

SILVIA MARÍA PÉREZ GONZÁLEZ Y JUAN CARLOS ARBOLEDA GOLDARACENA

Como cabe esperar, no todos los miembros de la sociedad sevillana que contaban con grados universitarios se habían formado en estas dos cátedras. Fue necesario acudir a aquellos lugares que contaban con estudios generales o universidades donde se impartiesen los estudios elegidos. El profesor Sánchez Herrero ha estudiado los clérigos y canónigos que asistieron a centros castellanos y extranjeros para cursar distintos estudios, así como la reglamentación que el cabildo catedralicio implementó en relación con estos estudiantes ${ }^{7}$. Las primeras noticias de capitulares sevillanos que estudiaban fuera datan del año 1313, fecha en la que el cabildo estableció los requisitos necesarios para poder obtener la licencia correspondiente. Más tarde, en 1395, se promulgó una reglamentación muy completa relativa a quienes se marchaban a estudiar en relación con las condiciones que debía reunir el candidato, la cuantía de lo que habían de cobrar los beneficiados, así como los casos particulares que pudiesen plantearse ${ }^{8}$.

El estudio de los registros notariales de Sevilla durante el período bajomedieval arroja datos interesantes. Recogemos los clérigos con formación universitaria de los que nos informa la documentación conservada en los protocolos. Entre los maestros en Sagrada Teología documentamos a Rodrigo Fernández de Santaella (1500)ํ. Varios son los bachilleres, sin que podamos especificar en qué materia: Alfonso de Logroño, canónigo de la catedral $(1480)^{10}$; Alfonso Pérez, cura de la iglesia de Santa Ana $(1500)^{11}$; Bartolomé de Morales, capellán de la iglesia de San Julián (1500) ${ }^{12}$; Diego de Oviedo, cura de la iglesia de San Vicente $(1503)^{13}$; Francisco Fernández, racionero de la catedral (1498) $)^{14}$; Francisco López, cura de la capilla de San Clemente $(1458)^{15}$; Francisco Núnez, capellán de los reyes $(1497)^{16}$; Juan García, clérigo (1496) ${ }^{17}$; Juan de la Torre, cura de Santa Cruz (1504) ${ }^{18}$; Juan Vázquez, canónigo de San Salvador $(1503)^{19}$; Pedro del Barco, cura de la catedral $(1504)^{20}$; y Pedro de Lobatón, capellán de la catedral $(1500)^{21}$.

Sánchez Herrero, José. «Centros de enseñanza y estudiantes de Sevilla durante los siglos XIII al xV». En la España Medieval, 1984, vol. 4, pp. 875-898.

8 Archivo Catedral de Sevilla. Secretaría. Estatutos. Libro 370. Ordenación del Cabildo (13541600). Ordenación XXXIX. Libro Blanco, fols. 125v.-128v.

9 Hazañas y La Rúa, Joaquín. Maese Rodrigo, 1444-1509. Sevilla: Imprenta de Izquierdo, 1909. Archivo Histórico Provincial de Sevilla (A.H.P.S.) Sección Protocolos. Leg. 4886, año 1504, fol. 223r; Leg. 1500, año 1502, fol. 217v; Leg. 1501, año 1504, fol. 901v; Leg. 2163, año 1503, fol. 367v; Leg. 2164, año 1503, fols. 59r y 268r; Leg. 2166, año 1504, fol. 463r.

10 A.H.P.S. Sección Protocolos. Leg. 4885, año 1480, fol. 33r; Leg. 2157, año 1500, fol. 546v; Leg. 2161, ańo 1502, fol. 30v; Leg. 2163, año 1503, fol. 232r.

11 A.H.P.S. Sección Protocolos. Leg. 2159, fol. 411v.

A.H.P.S. Sección Protocolos. Leg. 2158, año 1500, fol. 285v.

A.H.P.S. Sección Protocolos. Leg. 2164, año 1503, fol. $174 \mathrm{r}$.

A.H.P.S. Sección Protocolos. Leg. 17424, año 1498, fol. 215v.

A.H.P.S. Sección Protocolos. Leg. 17412, año 1458, fol. 15r.

A.H.P.S. Sección Protocolos. Leg. 1497, año 1497, fol. 169v.

A.H.P.S. Sección Protocolos. Leg. 1499, año 1501, fol. 586r.

A.H.P.S. Sección Protocolos. Leg. 3222, año 1504, fol. 33v.

A.H.P.S. Sección Protocolos. Leg. 17429, año 1470, sin foliar.

A.H.P.S. Sección Protocolos. Leg. 4886, año 1504, fol. 98r.

21 A.H.P.S. Sección Protocolos. Leg. 3219, ańo 1500, fol. 245 r. 
Algunos de los clérigos citados desempeñaron cargos importantes en distintas instituciones eclesiásticas. Alfonso de Logroño ${ }^{22}$ fue mayordomo del Hospital del Cardenal ${ }^{23}$; Francisco Núñez ejerció como juez pesquisidor de la Santa Cruzada ${ }^{24}$. En otros casos no podemos determinar si su actuación venía dada por su formación intelectual o por el reconocimiento social del que era objeto por la función parroquial que desempeńaba. Es el caso de Juan de la Torre, cura de Santa $\mathrm{Cruz}^{25}$, a quien Isabel de Roa nombró juez árbitro en cierto litigio. Otros simplemente fueron albaceas testamentarios ${ }^{26}$.

La documentación no nos permite dilucidar los centros universitarios en los que estudiaron. Quizás lo hicieran en universidades como la de Salamanca, Valladolid, Florencia, Roma, París, Bolonia, Aviñón y Montpellier, como sucedió con otros clérigos y capitulares estudiados por el profesor Sánchez Herrero ${ }^{27}$.

En el conjunto del clero regular destacan por sus estudios universitarios, como no podía ser de otra manera, los dominicos. La regla dominica exigía a los miembros de la Orden una formación intelectual elevada, de acuerdo con uno de los objetivos primordiales para los que nació la misma: la lucha contra los herejes ${ }^{28}$. Era necesario que los frailes gozasen de una excelente preparación en Sagrada Escritura y en Teología para poder combatir las doctrinas heterodoxas y poder formar al pueblo cristiano a través de la predicación sistemática. Los estudios cursados por los frailes de San Pablo ${ }^{29}$, de que nos informa la documentación, fueron los de Teología. Pero no todos ellos habían recibido esta formación, ni los que habían realizado estos estudios poseían el mismo grado. Entre los miembros de la casa que sí habían estudiado Teología encontramos a maestros como el prior fray Alfonso de Ojeda ${ }^{30}$, fray Alejo de Peñafiel ${ }^{31}$ y fray Juan de Cal de Ánimas ${ }^{32}$; doctores en Teología como fray Alfonso de Pancorvo ${ }^{33}$, fray Juan

22 A.H.P.S. Sección Protocolos. Leg. 4885, año 1480, fol. 33r.

23 Rubio Merino, Pedro. "Las constituciones del Hospital del Cardenal de Sevilla». Memoria Ecclesiae, 1997, vol. 10, pp. 349-375.

24 A.H.P.S. Sección Protocolos. Leg. 17422, año 1475, fol. $94 \mathrm{v}$.

25 A.H.P.S. Sección Protocolos. Leg. 3222, año 1504, fol. 33v.

26 A.H.P.S. Sección Protocolos. Leg. 17412, año 1458, fol. 15r.; Leg. 2164, año 1503, fol. 174r.

27 Sánchez Herrero, "Centros de enseñanza y estudiantes de Sevilla». Sánchez Herrero, José y Montes Romero-Camacho, Isabel. «Los colegiales sevillanos del Colegio Español de san Clemente de Bolonia (1368-1600)». En Estudio sobre los orígenes de las Universidades españolas. Homenaje de la universidad de Valladolid a la de Bolonia en su IX Centenario. Valladolid: Universidad de Valladolid, 1988, pp. 135-204.

28 Larios Ramos, Antonio. «Los dominicos y la Inquisición en Sevilla durante la Modernidad». Revista de Humanidades (Centro Asociado de la UNED de Sevilla), 2016, 27. Disponible en: http://www.revistadehumanidades.com/articulos/111-los-dominicos-y-la-inquisicion-en-sevilla-durante-la-modernidad

29 Huerga, Álvaro. Los dominicos en Andalucía. Sevilla: Convento de Santo Tomás de Aquino, 1992. Miura Andrades, José María. Frailes, monjas y conventos. Las órdenes mendicantes y la sociedad sevillana bajomedieval. Sevilla: Diputación de Sevilla, 1998, p.142. Sánchez Herrero, José. «Convento de San Pablo el Real de Sevilla». En Peñalver Gómez, Eduardo (coord.). Fondos y procedencia: Bibliotecas en la Biblioteca de la Universidad de Sevilla. Sevilla: Universidad de Sevilla, 2013, pp. 126-129.

30 A.H.P.S. Sección Protocolos. Leg. 3211, año 1483, fol. 15r.

31 A.H.P.S. Sección Protocolos. Leg. 3222, año 1504, fols. 185v y 533r; Leg. 3223, año 1504, fols. 338v, 353r y 358r.

32 A.H.P.S. Sección Protocolos. Leg. 3211, año 1483, fol. 5v.

33 A.H.P.S. Sección Protocolos. Leg. 3210, año 1441, fol. 10r; Leg. 2154, año 1494, fol. 23r. 
EL ACCESO A LA CULTURA Y LA FORMACIÓN INTELECTUAL EN ANDALUCÍA DURANTE LA BAJA EDAD MEDIA

SILVIA MARÍA PÉREZ GONZÁLEZ Y JUAN CARLOS ARBOLEDA GOLDARACENA

de Carmona ${ }^{34}$, fray Juan de San Juan ${ }^{35}$, fray Manuel de Sevilla ${ }^{36}$, fray Pedro de Sevilla ${ }^{37}$ y fray Juan de Zamora ${ }^{38}$; y un bachiller, fray Juan de Santa María ${ }^{39}$.

Como puede observarse, se trata de una proporción muy pequeña dentro de la amplia nómina de miembros del convento de que nos informa la documentación. Cabe la posibilidad de pensar que el escribano omitió los posibles grados académicos e intelectuales del resto de los frailes, pero no creemos que sea esta la explicación a un porcentaje tan bajo de frailes formados intelectualmente. Estamos ante una documentación muy minuciosa en detalles y tampoco tendría mucho sentido indicar los estudios de algunos miembros del convento y de otros guardar silencio. Quizás los omitidos gozaban de unos mínimos estudios que no merecieron la atención del notario.

La nómina de miembros del clero regular con formación universitaria es considerablemente inferior en el resto de los conventos. Para el de San Francisco ${ }^{40}$ solo se hace referencia a un maestro de Teología, fray Juan de Sevilla ${ }^{41}$, y nada más podemos afirmar de sus hermanos conventuales. Los frailes trinitarios ${ }^{42}$, debido a su labor de predicación de la cruzada a fin de recaudar las limosnas necesarias para el rescate de cautivos, necesitaban tener una preparación especial en Teología, Sagradas Escrituras, etc. En la nómina de trinitarios que nos ofrece la documentación encontramos distintos grados de formación intelectual en materias que no se especifican, pero que suponemos que debieron ser las indicadas. El porcentaje de frailes preparados intelectualmente es muy bajo, pues se trata de un número muy reducido en unas amplias listas de las que en la mayoría de los casos se omite cualquier tipo de indicación al respecto. Documentamos un maestro, fray Francisco ${ }^{43}$; varios doctores (fray Juan Canales ${ }^{44}$, fray Andrés de Burgos ${ }^{45}$, fray Fernando de Montealegree ${ }^{46}$, fray Cristóbal de Montealegre ${ }^{47}$, fray Juan de Santillana ${ }^{48}$, fray Leonardo de Úbeda ${ }^{49}$, fray

\section{Ibidem. \\ Ibidem. \\ Ibidem.}

Ibidem.

A.H.P.S. Sección Protocolos. Leg. 3211, año 1483, fol. 15r.

A.H.P.S. Sección Protocolos. Leg. 2156, ańo 1498, fol. 55v.

40 Rubio, Germán. La custodia franciscana de Sevilla. Ensayo histórico sobre sus orígenes, progresos y vicisitudes (1220-1499). Sevilla: San Antonio, 1952, pp. 56-60. Castillo Utrilla, María José del. El convento de San Francisco, Casa Grande de Sevilla. Sevilla: Diputación de Sevilla, 1988. Medianero Hernández, José María. El Convento "Casa Grande» de San Francisco de Sevilla y su repercusión en el ambiente cultural y artístico bajomedieval de la ciudad. Sevilla: Cajasur, 1997.

41 A.H.P.S. Sección Protocolos. Leg. 2161, año 1502, fol. 261r.

42 Morgado, Alonso de. Historia de Sevilla. Sevilla: Ayuntamiento de Sevilla, 2017, pp. 129-131. Aliaga Asensio, Pedro. «La Orden de la Santísima Trinidad en Sevilla». En Barrero González, Enrique y Martínez Carretero, Ismael (coords.). Órdenes y congregaciones religiosas en Sevilla. Sevilla: Ateneo de Sevilla, 2008, pp. 273-290.

43 A.H.P.S. Sección Protocolos. Leg. 2154, año 1494, fol. 116r.

44 A.H.P.S. Sección Protocolos. Leg. 9098, año 1448, fol. 324.

45 A.H.P.S. Sección Protocolos. Leg. 17424, año 1498, fol. 85r.

46 A.H.P.S. Sección Protocolos. Leg. 17421, año 1495, fol. 108v.

47 Ibidem.

48 Ibidem.

49 Ibidem. 
Álvaro de Villatoro ${ }^{50}$; un bachiller, fray Leonardo de Úbeda ${ }^{51}$; y un presentado, fray Cristóbal de Castro ${ }^{52}$.

Dentro de la nómina de frailes del convento de Santa María del Carmen ${ }^{53}$ encontramos algunos de ellos que gozaban de una formación intelectual. Dos de ellos eran presentados en Teología, como el prior fray Diego de San Juan de la Palma ${ }^{54}$ y fray Alfonso de Gijón ${ }^{55}$, y un bachiller, el prior fray Lucas ${ }^{56}$. Del resto de la comunidad conventual no se nos informa acerca de algún tipo de estudio cursado. Finalmente, en el convento del Espíritu Santo ${ }^{57}$ vivía un doctor, fray Fernán de Alfaro ${ }^{58}$, sin que se especifique la materia en la que había alcanzado el grado.

Aun teniendo en cuenta que los índices de formación intelectual son más altos en aquellos conventos mejor informados, estando absolutamente subordinados a la mayor o menor riqueza de las nóminas de frailes, podemos obtener dos conclusiones a partir de los datos manejados. En primer lugar, los porcentajes son bajos, lo que no creemos que sea resultado de una omisión sistemática del dato por parte de los escribanos públicos, cuyo gusto por el detalle y la máxima información está fuera de toda duda. Por otro lado, los miembros conventuales con determinados grados en los estudios de Teología son aquellos cuyas órdenes desarrollaban una labor de predicación, por lo que hacía de ellos una exigencia. Trinitarios, dominicos, mercedarios, carmelitas y franciscanos desarrollaron una intensa actividad pastoral en el seno de la sociedad en la que estaban incardinados, actividad que les exigía una especial formación para obtener los mejores resultados en los fines específicos por ellos desarrollados (lucha contra la herejía y rescate de cautivos).

La formación universitaria en Córdoba ha sido estudiada por la profesora Cabrera Sánchez ${ }^{59}$. En su estudio sobre los laicos que gozaban de una titulación cursada en la Universidad destacan los bachilleres, representando el $66 \%$ de los casos analizados, mientras que licenciados y doctores suponen el $20 \%$ y el $14 \%$, respectivamente. Pese al prestigio que suponía un título superior, muchos eran los estudiantes que tan solo aspiraban a adquirir una cierta formación que los capacitase para el desempeńo de diferentes tareas laborales. Buena parte de esos bachilleres lo eran en Derecho, disciplina que alcanzó un gran desarrollo a finales de la Edad Media ${ }^{60}$ y que permitía el acceso a un amplio elenco

50 A.H.P.S. Sección Protocolos. Leg. 2156, año 1498, fol. 170v.

51 A.H.P.S. Sección Protocolos. Leg. 17424, año 1498, fol. 115r.

52 A.H.P.S. Sección Protocolos. Leg. 17425, año 1500, fol. 240r.

53 Morgado, Historia de Sevilla, p. 137. Miura Andrades, Frailes, monjas y conventos, p. 147.

54 A.H.P.S. Sección Protocolos. Leg. 2155, año 1495, fol. 100v.

55 A.H.P.S. Sección Protocolos. Leg. 17423, año 1490, fol. 37v.

56 Ibidem.

57 Sancho de Sopranis, Hipólito. «La Orden de Sancti Spiritus en el Arzobispado hispalense (15001600)». Archivo Hispalense, 1961, vol. 35, n. ${ }^{\circ} 110$, pp. 234-237.

58 A.H.P.S. Sección Protocolos. Leg. 15963, año 1472, fol. 138v.

59 Cabrera Sánchez, Margarita. "El papel de los universitarios en la Córdoba del siglo XV». En Reglero de la Fuente, Carlos M. (coord.). Poder y sociedad en la Baja Edad Media hispánica. Estudios en homenaje al profesor Luis Vicente Diaz Martín. Valladolid: Universidad de Valladolid, 2002, pp. 333-356.

60 García García, Antonio. «La enseñanza reglada del Derecho durante la Baja Edad Media». Ínsula. Revista de Letras y Ciencias Humanas, 2003, n. ${ }^{\circ}$ 675, pp. 12-14. 
EL ACCESO A LA CULTURA Y LA FORMACIÓN INTELECTUAL EN ANDALUCÍA DURANTE LA BAJA EDAD MEDIA

SILVIA MARÍA PÉREZ GONZÁLEZ Y JUAN CARLOS ARBOLEDA GOLDARACENA

de profesiones. Les siguen los bachilleres en Medicina, Teología, Cánones, Gramática y Artes. Al igual que sucede en Sevilla, no es fácil conocer los centros donde estudiaron los universitarios cordobeses. Los pocos datos disponibles documentan la presencia de cordobeses en las Universidades de Salamanca y Valladolid.

Sumamente interesante es el estudio que la citada profesora realiza sobre los niveles socioeconómicos de los universitarios cordobeses ${ }^{61}$. Siguiendo la tendencia general de la Europa bajomedieval ${ }^{62}$, pocos fueron los miembros de la aristocracia que gozaban de estudios universitarios. Solo algunos integrantes de la nobleza seńorial, especialmente hijos segundones que ocuparon altas dignidades eclesiásticas, acudieron a las universidades para formarse. Entre ellos destacan Pedro de Solier, hijo del alcaide de los Donceles, y Lope Gutiérrez de los Ríos, hijo del señor de Fernán Núñez. Un segundo grupo de universitarios dentro de este estamento lo integran los miembros de la aristocracia urbana de tipo medio, en la que destacan los linajes de los Angulo y Aguayo.

Afirma la profesora Cabrera que en el caso de Córdoba gran parte de los poseedores de un título universitario pertenecían a los grupos intermedios. En su mayoría se trataba de juristas y médicos cuyos estudios les permitieron ascender socialmente e integrarse en los grupos oligárquicos. El importante ascenso social de los letrados durante el reinado de los Reyes Católicos también tuvo su eco en la Córdoba del momento. Varios cordobeses desempeñaron cargos muy destacados en la administración del reino castellano como Rodrigo del Cañaveral y Juan Díaz de Alcocer, oidores de la Real Audiencia ${ }^{63}$, entre otros muchos casos. Todos ellos evidencian la tendencia desarrollada a finales de la Edad Media de colocar a universitarios, especialmente letrados, en los oficios más destacados de la administración local como las alcaidías mayores y las regidurías.

Por otra parte, la Medicina conoció en la Córdoba de finales de la Edad Media un incremento en el número de profesionales que contaban con un título universitario en esta materia ${ }^{64}$. El grado alcanzado solía ser el de bachiller, siendo escasos los médicos que tenían la licenciatura o el doctorado, algunos de los cuales desempeñaron cargos muy destacados en el gobierno de la ciudad.

Jerez de la Frontera también contaba con una cátedra de Gramática que documentamos desde $1471^{65}$. En ese año el cabildo acordó enviar cartas al bachiller Juan de Mozas, quien había sido propuesto como maestro de dicha cátedra por el arzobispo de Sevilla, para que tomase posesión. La provisión de esta cátedra fue un problema constante durante el último cuarto del siglo xv. En 1490 había sido abandonada tanto por el doctor

61 Cabrera SÁnChez, «El papel de los universitarios», pp. 338-353.

62 Verger, Jacques. Gentes del saber en la Europa de finales de la Edad Media. Madrid: Editorial Complutense, 1999, p. 229. López Piñero, José María. «El renacimiento en las ciencias». En MenÉndez Pidal, Ramón. Historia de España. Tomo XXI. Madrid: Espasa, 1999, p. 314.

63 Garriga Acosta, Carlos Antonio. «La Real Audiencia y Chancillería de Valladolid». En Payo Hernanz, René Jesús y Sánchez Domingo, Rafael (coords.). El Régimen de justicia en Castilla y León: De Real Chancillería a Tribunal Superior. Burgos: Tribunal Superior de Justicia de Castilla y León, Junta de Castilla y León, 2014, pp. 13-98.

64 Cabrera SÁnchez, Margarita. «Médicos, cirujanos y curanderos en Córdoba durante la segunda mitad del siglo XV». Anuario de Estudios Medievales, 1996, vol. 26, n. ${ }^{o}$ 1, pp. 342-343.

65 Archivo Municipal de Jerez de la Frontera (A.M.J.F.) Actas Capitulares. 5 de junio de 1471, fol. 2r. 
Cisneros, que enseńaba en ella, como por el repetidor que había dejado en su puesto, por lo que el cabildo envió cartas al arzobispo para que nombrase un maestro ${ }^{66}$. Un año después era el doctor Asneros quien se ordenó de orden sacra y dejó el oficio de maestro en dicha cátedra, por lo que esta estaba vacante. Para el puesto se postuló Alonso Martínez Cordero, clérigo cura de la iglesia de San Lucas, por lo que el cabildo envió cartas al arzobispo para que supiese que la ciudad proponía como candidato al citado Alonso. En ellas se solicitaba que se determinase su idoneidad y, si así fuese, se le confirmase en el cargo ${ }^{67}$.

La información recogida en las actas capitulares evidencia el interés de los representantes del gobierno municipal por esta cátedra de Gramática. Además de los ejemplos analizados, siempre que el maestro de Gramática acudió al cabildo para atender ciertas necesidades de la misma, así como propias, los cabildantes atendieron sus peticiones expidiendo las cartas requeridas ${ }^{68}$.

\subsection{La enseñanza secundaria}

Esta fase es definida por el profesor Sánchez Herrero como los estudios que se cursaban entre el aprendizaje de la lectura, escritura y cuenta llana, y la Universidad. Se limitaba fundamentalmente a la enseñanza de Latín y en Sevilla tenía como centro de impartición el Estudio de San Miguel ${ }^{69}$.

El primer dato sobre este Estudio de Gramática se encuentra en un rótulo de concesión de beneficios dado en Aviñón en 1365. En él se documenta a Lorenzo Rodríguez de Villalpando, maestro de Gramática en Sevilla ${ }^{70}$. Pero las noticias concretas sobre el Estudio de San Miguel se remontan a los años 1414-1415, cuando el concejo hispalense pagó 1.000 maravedís al maestro de Gramática de la escuela de la ciudad ${ }^{71}$, y 1458, cuando se documenta esta institución con su nombre completo ${ }^{72}$. Por tanto, la existencia del Estudio es clara en el siglo Xv, pudiendo estar su origen en el siglo XIV.

El Estudio de San Miguel fue una fundación del cabildo catedralicio hispalense. Estaba dirigido por un maestro de Gramática que era clérigo o presbítero y recibía el nombramiento del canónigo maestrescuela de la catedral. No obstante, como hemos visto, era el concejo el que pagaba el salario de este maestro ${ }^{73}$. Igualmente se encontraba

66 A.M.J.F. Actas Capitulares. 5 de marzo de 1490, fol. 107v.

67 A.M.J.F. Actas Capitulares. 6 de abril de 1491, fol. 84r.

68 A.M.J.F. Actas Capitulares. 25 de febrero de 1484, fol. 144r; 4 de abril de 1484, fol. 109r.

69 Sánchez Herrero, De las primeras letras a la Universidad en la Sevilla, p. 61.

70 Beltrán de Heredia, Bulario de la Universidad de Salamanca, doc. n. ${ }^{\circ} 120$. Citado por: Sánchez Herrero, De las primeras letras a la Universidad en la Sevilla, p. 64.

71 Collantes de Terán, Francisco. Inventario de los Papeles del Mayordomazgo del siglo XV. Sevilla: Ayuntamiento de Sevilla, 1971, año 1414, 95. Citado por: SÁnchez Herrero, De las primeras letras a la Universidad en la Sevilla, p. 64.

72 Collantes de Terán, Inventario de los Papeles del Mayordomazgo del siglo XV, apéndice documental, 1. Citado por: SÁnchez Herrero, De las primeras letras a la Universidad en la Sevilla, p. 64.

73 Así sucedía también en el caso de Úbeda (Parejo Delgado, María Josefa. «El Colegio de los Niños de la Doctrina Cristiana y otras instituciones docentes en Úbeda en el siglo XvI». Hespérides. Anuario de Investigaciones, 1994, vol. 2, p. 77). 
EL ACCESO A LA CULTURA Y LA FORMACIÓN INTELECTUAL EN ANDALUCÍA DURANTE LA BAJA EDAD MEDIA

SILVIA MARÍA PÉREZ GONZÁLEZ Y JUAN CARLOS ARBOLEDA GOLDARACENA

situado en unas casas propiedad del cabildo catedralicio, frente a la puerta denominada del Nacimiento o de San Miguel.

Aunque algunos autores consideran que se enseñaron, además de Latín, otras materias como Filosofía, Artes liberales, Música, o Teología ${ }^{74}$, el profesor Sánchez Herrero sostiene que solo se enseñaba Latín. Era el maestro de Gramática, bajo la supervisión del canónigo maestrescuela, el encargado de su impartición, ayudado en la docencia por un bachiller.

Estos bachilleres también enseñaban privadamente mediante clases particulares. Conocemos el caso del bachiller Francisco Fernández, quien redactó su testamento el 23 de mayo de $1458^{75}$. Este bachiller acordaba con los progenitores de los alumnos lo que habían de pagarle anualmente por las clases, cantidad que podía ser satisfecha en dinero o en especie, en un solo plazo o trimestralmente, pudiendo darse el caso de que a final de año los padres o el bachiller no hubiesen cumplido la parte correspondiente de lo pactado. Entre sus alumnos hemos documentado un total de 16 de distinta procedencia, entre los que aparecen cinco denominados criados, término que hemos de entender dentro del contexto histórico en el que nos encontramos, es decir, jóvenes que vivían en casa de quienes recibían una formación, en este caso en latín, a cambio de ciertos servicios domésticos ${ }^{76}$.

En Córdoba la enseñanza secundaria se impartía en un Estudio General de Gramática. Se documenta por primera vez en 1313 dependiente del obispo y el cabildo catedralicio, que antes de 1387 había recibido privilegio que le otorgaba la exclusividad de este Estudio en Córdoba ${ }^{77}$. En él se estudiaban, además de Gramática, Lógica, Filosofía y, quizás, Derecho y otras materias. El proceso de aprendizaje se desarrollaba a lo largo de cuatro años.

Además de este Estudio existían en Córdoba otras escuelas de Gramática que no dependían del cabildo catedralicio. Este defendió su exclusividad alegando que los maestros de estas escuelas no tenían la titulación necesaria y que los estudiantes que terminaban sus estudios estaban escasamente formados. En cualquier caso, el cabildo reconocía el derecho a tener un maestro particular siempre que este enseñase en casa de la familia que lo contrataba y solo a sus hijos ${ }^{78}$.

De la catedral de Jaén también dependía una Escuela de Gramática ${ }^{79}$. Al frente de la misma se encontraba el maestro, quien era elegido por el maestrescuela ${ }^{80}$. Los estatutos

74 Ladero Quesada, Miguel Ángel. Historia de Sevilla. La ciudad medieval. Sevilla: Universidad de Sevilla, 1976, p. 189. Morales Padrón, Francisco. Historia de Sevilla. La ciudad del Quinientos. Sevilla: Universidad de Sevilla, 1977, pp. 275-285.

75 A.H.P.S. Sección Protocolos. Leg. 17412, año 1458, fol. 15r.

76 Barron, Caroline M. «The Education and Training of Girls in Fifteenth Century London». Courts, Counties and the Capital in the Later Middle Ages. New York: Sutton Publishing Company, 1996, pp. 139-153. García Herrero, Carmen. Las mujeres en Zaragoza en el siglo XV. 2. a ed. 2 vols. Zaragoza: Prensas Universitarias de Zaragoza, 2006, pp. 115-116.

77 Escobar Camacho, José Manuel. «La educación en Córdoba durante la Baja Edad Media: La enseñanza primaria». Incabo, 1985, vol. 5, p. 40.

78 Ibidem, p. 41.

79 García Pardo, Manuela. «La cultura clerical en el obispado de Jaén en la Baja Edad Media». Hispania Sacra, 1999, vol. 51, n. ${ }^{\circ} 104$, p. 712.

80 El Cabildo no siempre cumplió esta función de forma adecuada, por lo que otros miembros de la sociedad jienense, como el condestable Miguel Lucas de Iranzo, se preocuparon de financiar un maestro de 
catedralicios recogen las cualidades que debía reunir todo aspirante al cargo: una correcta preparación, que supiera leer perfectamente, que fuera capaz de trabajar diligentemente para que los alumnos adquiriesen los conocimientos en el menor tiempo posible y con la máxima profundidad, y que cumpliese el calendario escolar que iba desde el día de san Lucas hasta la festividad de santa María Magdalena. Su sueldo era pagado por la catedral, estableciéndose también que cada alumno, excepto los pobres que eran mantenidos mediante las limosnas aportadas por la feligresía, debía pagar al maestro 200 maravedís.

En el obispado de Jaén también se contemplaba la posibilidad de establecer escuelas creadas por laicos o dependientes de una institución no eclesiástica. En ellas se había de enseñar, además de Gramática, los principios de la doctrina cristiana. Por ello se consideraba conveniente que estuviesen cercanas a alguna iglesia, para así facilitar la asistencia de los alumnos a los oficios divinos ${ }^{81}$.

\subsection{La enseñanza primaria}

A pesar de que durante la Baja Edad Media asistimos a un gran desarrollo cultural, que se plasmó, entre otros aspectos, en el nacimiento y difusión de las Universidades, por el contrario la enseñanza primaria permaneció estancada. La principal razón radica en que no se crearon centros adecuados para su impartición en las ciudades. Casi no había ninguna institución en la que se pudiera aprender a leer, escribir o adquirir algunas nociones de cálculo. La única opción era contratar una formación privada, lo que excluía a muchos miembros de la sociedad urbana que carecían de la capacidad económica necesaria.

En el ańo 1998, los profesores Sánchez Herrero y Pérez González publicaron un trabajo sobre la enseñanza de las primeras letras en Sevilla durante el siglo $\mathrm{xv}^{82}$. A partir de 24 protocolos notariales se estudian diferentes aspectos de la enseñanza primera como los maestros (quienes figuran con las denominaciones de bachiller de Gramática ${ }^{83}$, maestro de mostrar leer y escribir ${ }^{84}$, maestro de maestros ${ }^{85}$, escribano de enseñar mozos ${ }^{86}$, escribano y maestro de enseńar mozos a leer y escribir ${ }^{87}$, así como un clérigo y un cambiador ${ }^{88}$ ), la remuneración por ellos percibida de acuerdo con los diferentes tipos de contratos suscritos (contrato de aprendizaje de leer y escribir, contrato de residencia del alumno

Gramática (CArriazo, Juan de Mata. Hechos del condestable Miguel Lucas de Iranzo. Madrid: Marcial Pons, 2009, p. 453).

${ }_{81}$ Ibidem, p. 715.

82 SÁnchez Herrero, José y Pérez González, Silvia María. «Aprender a leer y escribir. Libros y libreros en la Sevilla del último cuarto del siglo Xv». Edad Media. Revista de Historia, 1998, vol. 1, pp. 47-90.

83 A.H.P.S. Sección Protocolos. Leg. 3215, año 1495, fol. 22v.

84 A.H.P.S. Sección Protocolos. Leg. 2157, año 1500, fol. 75r; Leg. 2158, año 1500, fol. 303r.

85 A.H.P.S. Sección Protocolos. Leg. 9101, año 1504, fol. 276v.

86 A.H.P.S. Sección Protocolos. Leg. 17419, año 1493, fols. 108r y 109r.

87 A.H.P.S. Sección Protocolos. Leg. 2154, año 1494, fol. 481v; Leg. 17426, año 1500, fol. 96r; Leg. 1499, año 1500, fol. 130r.

88 A.H.P.S. Sección Protocolos. Leg. 15963, año 1472, fol. 245v. 
EL ACCESO A LA CULTURA Y LA FORMACIÓN INTELECTUAL EN ANDALUCÍA DURANTE LA BAJA EDAD MEDIA

SILVIA MARÍA PÉREZ GONZÁLEZ Y JUAN CARLOS ARBOLEDA GOLDARACENA

y contrato de servicio y aprendizaje), la enseńanza impartida (leer en romance y latín, leer una carta, leer letra llana de mano, leer letra redonda, leer letra tirada, leer letra de molde, escribir una carta, escribir en letra redonda, escribir en letra tirada, cuenta llana) y la duración de la misma (normalmente un año). Por lo que se refiere a los alumnos se analiza su edad, así como su filiación con el otorgante del contrato.

Este estudio podemos completarlo con dos nuevos documentos hallados en Jerez de la Frontera. Se trata de dos contratos suscritos por Álvaro de Sevilla, al que se denomina maestro de escuela de mostrar mozos a leer y escribir, quien en un caso se comprometió a enseñar a leer y escribir a Sebastián, hijo de Sebastián García, durante un año cada sábado por 10 maravedís semanales ${ }^{89}$. Once años después volvió a suscribir otro contrato por el que se contrató para enseñar a Juan de Alba, hijo de Bernal Martín de Alba, a leer y escribir una carta por una cuantía de 12 reales de plata, pagados trimestralmente, más un maravedí cada sábado y los presentes de las Pascuas ${ }^{90}$. El documento es sumamente interesante porque hace referencia a la escuela que tenía Álvaro de Sevilla, una de las muy escasas que hemos podido constatar. El tiempo de la enseñanza no se precisa, tan solo se indica el que fuere necesario, pues el objetivo era que el discente adquiriese las competencias necesarias para convertirse en escribano. Al igual que en el resto del Occidente europeo, la enseñanza estaría basada en la repetición y el ejercicio constante ${ }^{91}$.

En Córdoba existían dos vías para el acceso a la educación primaria. Una de ellas era la escuela catedralicia dedicada a la enseñanza de la lectura y la música fundamentalmente. Sus alumnos eran los niños de coro y, en algunas ocasiones, miembros del cabildo que eran incapaces de leer o cantar ${ }^{92}$. La segunda opción eran los maestros privados que las familias, fundamentalmente las que contaban con cierta capacidad económica, contrataban para sus hijos. El estudio realizado por Escobar Camacho ${ }^{93}$ revela unas características muy similares a lo que ocurría en Sevilla por las mismas fechas en lo que se refiere a materias impartidas, edad de los alumnos o el pago al maestro. La única diferencia se encuentra en el tiempo de duración del aprendizaje, pues mientras que en Sevilla los contratos se fijan en un año generalmente, en Córdoba se estipula en dos o tres años.

\section{LiBRos y BIBLIOTECAS}

En el acceso a la cultura ocupan un papel fundamental los libros ${ }^{94} \mathrm{y}$ bibliotecas como instrumentos de transmisión del saber. Nos ocupamos en este apartado de conocer la creciente presencia de libros dentro de la realidad social andaluza bajomedieval,

89 A.M.J.F. Protocolos notariales. Bartolomé de Maya. 11 de agosto de 1490, fol. 241v.

90 A.M.J.F. Protocolos notariales. Juan Román. 15 de septiembre de 1501, fol. 372r.

91 Gimeno Blay, Francisco M. «Aprender a escribir en la Península Ibérica: de la Edad Media al Renacimiento». En Petrucci, Armando y Gimeno Blay, Francisco M. (eds.). Escribir y leer en Occidente. Valencia: Universidad de Valencia, 1995, pp. 134-135.

92 Escobar Camacho, «La educación en Córdoba durante la Baja Edad Media», p. 40.

93 Ibidem, p. 43.

94 GellRich, Jesse M. The idea of the book in the Middle Ages: language, theory, mythology and fiction. New York: Cornell University Press, 1987. 
los autores conocidos en la época y la formación de bibliotecas, verdaderos centros de concentración del saber, ligadas sobre todo a la nobleza y a las instituciones eclesiásticas.

El uso y posesión de libros en la vida cotidiana puede pulsarse a través de la consulta de la documentación notarial. Para los casos sevillano y jerezano hemos podido documentar distintos testamentos en los que se hace mención a los libros como parte de los diversos legados. En Sevilla, Pedro Martínez, clérigo, deja en su testamento dos libros a Andrés González y Juan de Morales, ambos clérigos también. El primero de ellos recibió un ejemplar llamado Postula y el segundo un Sacramental ${ }^{5}$. Alfonso Pérez de las Heras, clérigo cura de la iglesia de Santa Ana en Triana, tenía en su casa una pequeña biblioteca con ciertos libros «entre chicos y grandes» ${ }^{96}$. En otros testamentos sevillanos se documenta también la donación de diversos libros ${ }^{97}$, entre los que se cuentan libros de rezar que se donan a distintas iglesias, como Santiago de la Espada, en $1458^{98}$. También encontramos una relación de bienes de fray Fernando de Montelegre, fraile del convento de la Trinidad, entre los que se encuentran doce libros ${ }^{99}$.

En el caso de Jerez de la Frontera hemos podido documentar también donaciones de libros, como la de Sancho Díaz, beneficiado de la iglesia de San Lucas, que lega a su sobrino todos sus libros ${ }^{100}$. Igualmente la documentación notarial nos habla del uso de libros por parte de los testadores: fray Antón, fraile del monasterio de Santa María de la Merced, se hacía cargo de los libros de dicho monasterio -entendemos que aquellos relacionados con la liturgia- en su función de sacristán ${ }^{101}$; Martín Sánchez Naharro tenía un libro donde estaba apuntada la cantidad que le debía la Casa de la Cartuja ${ }^{102}$; Pedro García de Barja tenía también un libro donde contabilizaba las deudas relacionadas con trabajos y ganado ${ }^{103}$. Sendos libros para anotar deudas tenían igualmente Bartolomé Camacho $^{104}$ y Juan Martínez de Villavicencio ${ }^{105}$. En 1392 documentamos también la posesión de un Doctrinal ${ }^{106}$.

La producción de libros constituía una actividad importante dentro del sector artesanal en los distintos ambientes urbanos. Para el caso de Sevilla, los profesores Sánchez Herrero y Pérez González ${ }^{107}$ documentaron, entre los años 1478 y 1510, la presencia

95 A.H.P.S. Sección Protocolos. Leg. 2163, fol. 191r.

96 A.H.P.S. Sección Protocolos. Leg. 2159, fol. 411v.

A.H.P.S. Sección Protocolos. Leg. 2163, año 1503, fol. $191 \mathrm{r}$.

8 A.H.P.S. Sección Protocolos. Leg. 17412, año 1458, fol. 30v.

99 A.H.P.S. Sección Protocolos. Leg. 17425, fol. 102r.

100 A.M.J.F. Protocolos notariales. Bartolomé de Maya. Martes 5 de mayo de 1489, fol. 81v.

101 A.M.J.F. Protocolos notariales. Gonzalo Román. Miércoles 18 de septiembre de 1471, fol. 426v.

102 A.M.J.F. Protocolos notariales. Bartolomé de Maya. Lunes 13 de julio de 1489, fol. 147r.

103 A.M.J.F. Protocolos notariales. Bartolomé de Maya. Miércoles 4 de agosto de 1490, fol. $225 \mathrm{r}$.

104 A.M.J.F. Protocolos notariales. Juan Ortega Gaitán. Jueves 8 de julio de 1490, fol. 104v.

105 A.M.J.F. Protocolos notariales. Juan Ortega Gaitán. Sábado 7 de julio de 1490, fol. 118r.

106 A.M.J.F. Protocolos notariales. Lope Martínez. Viernes 12 de abril de 1392, fol. 9v. RoJAs VACA, María Dolores. Un registro notarial de Jerez de la Frontera (Lope Martínez, 1392). Madrid: Fundación Matritense del Notariado, 1998.

107 SÁnchez Herrero, José y Pérez González, Silvia María. «Las gentes del saber o del libro en Sevilla entre 1478 y 1510». En Andalucía medieval: actas del III Congreso de Historia de Andalucía. Córdoba: Cajasur, 2003, vol. 6, pp. 453-469. 
EL ACCESO A LA CULTURA Y LA FORMACIÓN INTELECTUAL EN ANDALUCÍA DURANTE LA BAJA EDAD MEDIA

SILVIA MARÍA PÉREZ GONZÁLEZ Y JUAN CARLOS ARBOLEDA GOLDARACENA

de nueve escribanos de letra de obra (escritor de libros para su publicación y difusión), tres iluminadores, varios impresores (fundamentalmente alemanes), diecinueve libreros y diversos mercaderes que comerciaban con libros y papel. También documentan varios contratos de aprendizaje vinculados a estos oficios. La catedral de Sevilla contaba también con un numeroso colectivo de productores de libros vinculados a esta institución eclesiástica ${ }^{108}$.

En cuanto a los autores andaluces o relacionados con Andalucía de finales de la Edad Media, es nuevamente el profesor Sánchez Herrero quien elabora un elenco bastante completo de los mismos, destacando en Gramática el célebre Elio Antonio de Nebrija (1441-1552); en Filosofía, Fernando de Córdoba (1421/26-1485/87); en Teología, san Pedro Pascual, obispo de Jaén (1225-1300); y en Catequesis y moral, fray Hernando de Talavera, primer arzobispo de Granada (1430-1507) ${ }^{109}$.

Por cuanto respecta a las bibliotecas, estas estuvieron ligadas fundamentalmente a la nobleza o a las instituciones eclesiásticas. Aunque el número de bibliotecas conocidas no era muy amplio, para el caso andaluz destacaron algunas importantes como la de don Alfonso Tenorio, adelantado de Cazorla, que es la primera de estas colecciones conocidas en Castilla y atesoraba un total de veinticuatro libros ${ }^{110}$; la de Alvar Pérez de Guzmán, alguacil mayor de Sevilla y señor de Orgaz, con unos treinta ejemplares ${ }^{11}$; la de la familia Sotomayor de Belalcázar ${ }^{112}$; la de los Guzmanes de Córdoba, con catorce libros ${ }^{113}$; o la del marqués de Priego, con nada menos de 309 volúmenes ${ }^{114}$. Más numerosos fueron los ejemplares conservados en bibliotecas eclesiásticas, como las del Colegio de Santo Tomás de Aquino o del Convento de San Pablo de Sevilla ${ }^{115}$; o la de la propia seo hispalense ${ }^{116}$.

En cuanto a la temática de los libros presentes en estas bibliotecas, podemos tomar como referencia el mencionado trabajo de Quintanilla ${ }^{117}$ sobre la biblioteca del marqués

108 Álvarez Márquez, María del Carmen. «Los artesanos del libro en la catedral hispalense durante el siglo XV». Archivo Hispalense, 1987, vol. 70, n. ${ }^{\circ}$ 215, pp. 3-36.

109 SÁnchez Herrero, José. «Entre el creer y el saber. Autores de Andalucía de los siglos XIV y XV». En Malpica, Antonio et ál. (coords.). Historia de Andalucía, VII Coloquio. Granada: Universidad de Granada, 2009, pp. 147-178.

110 Beceiro Pita, Isabel y Franco Silva, Alfonso. «Cultura nobiliar y bibliotecas: cinco ejemplos, de las postrimerías del siglo xIv a mediados del XvI». Historia. Instituciones. Documentos, 1985, vol. 12, pp. 277-350.

111 Ibidem.

112 Cabrera Muñoz, Emilio. «La fortuna de una familia noble castellana, a través de un inventario de mediados del siglo Xv». Historia. Instituciones. Documentos, 1975, vol. 2, pp. 9-42.

113 Cabrera Sánchez, Margarita. «La nobleza andaluza de finales de la Edad Media: los Guzmanes de Córdoba». Historia. Instituciones. Documentos, 2006, vol. 33, pp. 9-48.

114 Quintanilla Raso, María Concepción. «La biblioteca del marqués de Priego (1518)». En la España Medieval, 1980, vol. 1, pp. 347-383.

115 Sánchez Herrero, José. «Las bibliotecas del Colegio de Santo Tomás de Aquino y del Convento de San Pablo de la orden dominica en la ciudad de Sevilla». En Córdoba de la Llave, Ricardo et ál. (coords.). Estudios en homenaje al profesor Emilio Cabrera. Córdoba: Universidad de Córdoba, 2015, pp. 545-572.

116 Álvarez Márquez, María del Carmen. «La biblioteca de la catedral Hispalense en el siglo XV». Archivo Hispalense, 1987, vol. 70, n. ${ }^{\circ} 213$, pp. 3-68.

117 Quintanilla Raso, «La biblioteca del marqués de Priego (1518)». 
de Priego por la abundancia de ejemplares que conservaba. Además de las obras de carácter religioso, que eran las más abundantes, destacan aquellas enfocadas a otras ramas del saber como la literatura latina clásica, los estudios históricos, la retórica, la filosofía, las humanidades en general, la didáctica o la medicina. En menor medida también había ejemplares dedicados a otras disciplinas como la geografía, el derecho, la historia natural, la agronomía o la mitología.

\section{Mujeres y Cultura}

El tema que abordamos en este apartado es sumamente complejo, debido a razones de carácter eminentemente heurístico. Resulta enormemente complicado encontrar evidencias documentales sobre mujeres con formación intelectual y sobre sus vínculos con los instrumentos de la cultura. No obstante, poseemos algunas noticias que permiten hacernos una idea somera de cómo pudieron las mujeres participar del agitado ambiente cultural de la Andalucía de finales de la Edad Media.

El concepto de educación en la Edad Media es muy amplio y general. Su objetivo era modelar a las personas a partir de determinados principios tanto religiosos como laicos. En un primer nivel consistía en el aprendizaje de un conjunto de normas sociales que permitían al individuo alcanzar una determinada posición en la sociedad. Quien no adquiría tal formación se convertía en un marginado ${ }^{118}$. El segundo nivel, que es el que se ajusta al objetivo de nuestra investigación, estaba integrado por la enseñanza de la lectura y la escritura. A esta instrucción accedían pocas mujeres, puesto que no era un requisito exigido por la sociedad. De hecho, dentro del ámbito de la enseñanza las noticias relativas a mujeres son escasísimas. Tan solo hemos documentado un contrato ${ }^{119}$ en el que un maestro, Alfonso Escudero, se compromete a enseñar a una niña, Isabel, hija del genovés Silvestre Vento. La habilidad que debía ser mostrada era leer en romance y en latín, sin que se establezca el tiempo que debía durar la enseñanza. Tan solo se indica que la niña recibiría dos lecciones diarias y el maestro cobraría un castellano de oro cuando Isabel fuese capaz de leer. Como puede observarse, esta instrucción era recibida a través de una figura masculina ${ }^{120} \mathrm{y}$ de forma receptiva.

Estamos seguros de que en el resto de las ciudades andaluzas debieron firmarse contratos de enseñanza en los que los aprendices fuesen miembros femeninos, obviamente en una cuantía mucho menor que los destinados a varones. Muestra de ello son las referencias que aparecen en algunos testamentos a libros de ejecución personal denominados de cuenta ${ }^{121}$.

118 Cuadra García, Cristina; Graña Cid, María del Mar; Muñoz Fernández, Ángela y Segura Graíño, Cristina. "Notas a la educación de las mujeres en la Edad Media». En Graña Cid, María del Mar (coord.). Las sabias mujeres: educación, saber y autoría (siglos III-XVII). Madrid: Asociación Cultural Al-Mudayna, 1994, p. 33-34.

119 A.H.P.S. Sección Protocolos. Leg. 9101, año 1504, fol. 276v.

120 A diferencia de otros lugares, no hemos documentado en Andalucía ninguna maestra (GARCía Herrero, María del Carmen. Las mujeres en Zaragoza en el siglo XV. Zaragoza: Ayuntamiento de Zaragoza, 1990, v. I, p. 127).

121 A.M.J.F. Protocolos notariales. Juan Ortega Gaitán. 29 de marzo de 1491, fol. 42v. 
EL ACCESO A LA CULTURA Y LA FORMACIÓN INTELECTUAL EN ANDALUCÍA DURANTE LA BAJA EDAD MEDIA

SILVIA MARÍA PÉREZ GONZÁLEZ Y JUAN CARLOS ARBOLEDA GOLDARACENA

En dichos libros confeccionados por las testadoras, donde desarrollaron las competencias de escritura y cálculo adquiridas gracias a una enseñanza primaria que recibieron seguramente cuando eran niñas, recogieron una serie de deudas que les debían ser resarcidas o ellas debían saldar.

Algunas noticias más poseemos sobre la relación de las mujeres con los libros ${ }^{122}$. En este sentido destacan los miembros de la religiosidad femenina laica, especialmente beatas y emparedadas. Ambas manifestaciones religiosas están protagonizadas por mujeres pertenecientes a los sectores intermedios de sus respectivas sociedades urbanas, a diferencia de los miembros del monacato que en las fechas estudiadas presentaban un carácter aristocrático. Tanto beatas como emparedadas propusieron fórmulas alternativas a las estructuras imperantes, constituyendo una forma de vida independiente y autónoma con respecto a la familia y las instituciones eclesiásticas. Encontraron opciones libres de la potestad masculina, lograron hacerse reconocer como colectivo social y consiguieron la independencia vital, patrimonial y laboral ${ }^{123}$. Por otro lado, este modelo alternativo al monacato contaba con un importante componente apostólico que permitía combinar la acción y la contemplación, implementando un extraordinario elenco de ámbitos de actuación fuera de los claustros ${ }^{124}$.

Afirma la profesora Graña Cid que las beatas actuaron como agentes de un sistema de transmisión pastoral en la que gozaban de una doble función como transmisoras y receptoras. Al difundirse dentro de estos grupos la práctica de la oración individual, se extendió al mismo tiempo una red de libros devotos cuya lectura resultaba imprescindible para el desarrollo de la citada oración. A los ejemplos cordobeses que recoge la citada profesora de dos beatas poseedoras de libros (Inés García de Requena tenía un libro de horas, un libro de san Francisco y un libro sobre san Fulgencio ${ }^{125}$; Constanza Rodríguez donó a las monjas cistercienses el libro de horas escrito en papel con el que rezaba ${ }^{126} ; \mathrm{y}$ Constanza Rodríguez legó a su sobrina un libro de horas ${ }^{127}$ ) podemos sumar otros procedentes de Sevilla y Jerez de la Frontera.

En el emparedamiento de la iglesia del convento de Santiago de la Espada de Sevilla vivía Juana de Santa María ${ }^{128}$, quien en 1488 dictó su testamento ${ }^{129}$. En él declaraba que

122 GraÑa Cid, María del Mar. «¿Leer con el alma y escribir con el cuerpo? Reflexiones sobre mujeres y cultura escrita». En Castillo Gómez, Antonio (coord.). Historia de la cultura escrita. Del Próximo Oriente Antiguo a la sociedad informatizada. Gijón: Trea, 2002, pp. 385-452.

123 Pérez González, Silvia María. "Las mujeres de la muy noble y muy leal ciudad de Jerez de la Frontera. Siglos Xiv-Xvi». En SÁnchez Herrero, José y González Jiménez, Manuel (dirs.). 750 aniversario de la incorporación de Jerez a la Corona de Castilla: 1264-2014. Jerez de la Frontera: Ayuntamiento, 2014, p. 304.

124 Graña Cid, María del Mar. «Beatas y comunidad cívica. Algunas claves interpretativas de la espiritualidad femenina urbana bajomedieval (Córdoba siglos XIv-Xv)». Anuario de Estudios Medievales, 2012, vol. 42 , n. ${ }^{\circ}$ 2, p. 714 .

125 Graña Cid, María del Mar. «El Císter femenino bajomedieval: contenidos carismáticos y funcionalidades políticas (Córdoba, 1260-1510)». Cistercium, 2010, vol. 254, p. 252.

126 Ibidem, p. 253.

127 Graña Cid, «Beatas y comunidad cívica», p. 716.

128 Citado por Miura Andrades, Frailes, monjas y conventos, p. 241.

129 A.H.P.S. Sección Protocolos. Leg. 9100, año 1488, fol. 311r. 
poseía un altar con algunas imágenes ante las que oraba cada día con sus libros de rezo (hemos de deducir que contaba con varios) y sus «cuentas de rezar». En Jerez de la Frontera el clérigo Alfonso de Vanades ${ }^{130}$, capellán de la iglesia de San Miguel, donó al emparedamiento que estaba adosado a la citada parroquia un libro titulado Flos Sanctorum. El hecho de que el clérigo y las emparedadas estuviesen vinculados al mismo templo pudo generar entre ellos relaciones de amistad que explican este regalo de especial valor en la época que estudiamos, un libro. Al mismo tiempo recordemos que en una época en la que se cuestionaba si era apropiado que las mujeres leyesen ${ }^{131}$, se consideraba que los libros más útiles para ellas eran los libros de temática religiosa obviamente escritos por hombres ${ }^{132}$. Pero realmente no podemos afirmar si los leían o les eran leídos, aunque ciertamente conocían algunos de ellos ${ }^{133}$.

Esta presencia de los libros destinados al rezo nos lleva a reflexionar sobre el hecho de que la literatura, durante la Edad Media, no puede ser definida adecuadamente sin tener en cuenta que la palabra escrita estaba incrustada en la oralidad a través de muy diversos cauces. El texto escrito podía ser dictado, comunicado y discutido oralmente. Incluso la lectura así mismo podría implicar la vocalización de las palabras en la página, como sucedía en el caso de los libros de oración ${ }^{134}$. De esta forma la palabra escrita también tenía una dimensión hablada y auditiva, al tiempo que la palabra hablada estaba implicada en los dominios alfabetizados de la escritura y la percepción visual ${ }^{135}$.

Otro vínculo que las religiosas laicas tejieron con la cultura fue su preocupación por la formación intelectual de algunos miembros de su familia. Sería el caso de Teresa Muñiz, beata del beaterio dominico de las Bañuelas de Córdoba, quien había criado a su sobrino Fernán Mejía de las Infantas ${ }^{136}$. Se comprometió a proveerlo de ropa y, dato sumamente interesante, de libros y atenderlo en sus necesidades durante toda su vida en caso de que optase por la vida conventual. Con este compromiso Teresa está evidenciando que era plenamente consciente de la importancia que la cultura podía tener en la proyección dentro de su Orden de un religioso, estando dispuesta a costear los libros necesarios para ello.

Fuera de los colectivos de mujeres religiosas también encontramos otros miembros femeninos de la sociedad andaluza vinculados al mundo del libro. Es el caso de la sevillana

130 A.M.J.F. Protocolos notariales. Bartolomé de Maya. 3 de septiembre de 1489, fol. 19r.

131 Green, Dennis Howard. Women readers in the Middle Ages. Cambridge: Cambridge University Press, 2007, pp. 84-90.

132 Barttlet, Anne Clark. Male Authors, Female Readers: Representation and Subjectivity in Middle English Devotional Literature. New York: Cornell University Press, 1995.

133 Uno de estos libros que recoge la documentación (A.M.J.F. Protocolos notariales. Bartolomé de Maya. Domingo 21 de julio de 1490, fol. 202v) es la Vida de san Pantaleón. La testadora, Leonor Martínez, pidió que celebrasen por su alma 30 misas cantadas según están escritas en la Vida de san Pantaleón. ¿Las había leído o le habían sido referidas? No podemos responder a este interrogante.

134 Green, Dennis Howard. Medieval listening and Reading. Cambridge: Cambridge University Press, 1994, p. 15. 2005, p. 4.

135 Chinca, Mark y Young, Christopher. Orality and literacy in the Middle Ages. Turnhout: Brepols,

136 Graña Cid, María del Mar. «Beatas dominicas y frailes predicadores. Un modelo religioso bajomedieval de relación entre los sexos (Córdoba, 1487-1550)». Archivo Dominicano, 2011, vol. 32, p. 239. 
EL ACCESO A LA CULTURA Y LA FORMACIÓN INTELECTUAL EN ANDALUCÍA DURANTE LA BAJA EDAD MEDIA

SILVIA MARÍA PÉREZ GONZÁLEZ Y JUAN CARLOS ARBOLEDA GOLDARACENA

Mari Díaz, quien encargó a Juan de Pedralosa ${ }^{137}$, capellán de la catedral, la confección de un misal. En el momento en que la citada cliente redactaba su testamento ya había acabado la parte de la escritura y solo le faltaba la iluminación. Ella mandó en su última voluntad que le tomasen juramento de que lo iba a acabar de confeccionar y entregar a los beneficiados de la iglesia de San Vicente, a quienes estaba destinado. Por tanto, estamos ante una mujer que actuó como agente promotor de instrumentos culturales aun cuando no estuviesen destinados a su vida personal.

A diferencia de estas evidencias de la existencia de mujeres lectoras en la Andalucía de finales de la Edad Media, no atestiguamos ningún caso de escritoras literarias. No contamos con ningún escrito obra de alguna mujer, en el que podamos comprobar si cumplían las características comunes a las obras salidas de manos femeninas como Eloísa, Hildegarda de Bingen, Dhuoda o Gertrud de Helfta, entre otras ${ }^{138}$. Entre ellas una motivación que casi nunca es predominantemente literaria, sino que es la respuesta a unas necesidades personales más que a una inclinación didáctica o artística. Al mismo tiempo las obras femeninas evidencian una falta de apriorismo de posturas predeterminadas y se trata de intentos de hacer frente a los problemas humanos en su singularidad, no imponiendo reglas o categorías desde fuera sino buscando soluciones que resultaran aptas y veraces existencialmente ${ }^{139}$.

\section{Conclusiones}

La Universidad de Sevilla se fundó en 1505. Este gran hito fue posible porque en la Andalucía de finales de la Edad Media se había desarrollado el ambiente propicio para ello. La cultura, sus gentes y sus agentes habían alcanzado un nivel con la excelencia necesaria como para que una institución universitaria pudiera comenzar su andadura en tierras andaluzas y con garantías de éxito.

La situación de la enseñanza en la Andalucía bajomedieval se caracteriza por una amplísima gama de posibilidades en muchos casos no fácilmente definibles. Los centros de enseñanza no estaban plenamente establecidos y muchos de ellos, como las cátedras de Gramática, se vieron sometidos a continuas inestabilidades provocadas por el abandono de los maestros. No obstante, los poderes municipales mostraron un especial interés por ellos al financiarlos, atender las demandas de los maestros y solicitar a la autoridad competente la provisión de la plaza vacante. En el caso de la enseñanza primaria muchos espacios privados acababan convirtiéndose en improvisadas escuelas.

Por otro lado, especialmente en los primeros niveles de la docencia, no había un modelo único de aprendizaje. Las competencias que los alumnos debían adquirir varían según los contratos, así como el tiempo de logro de las mismas. Esta carencia normativa

137 A.H.P.S. Sección Protocolos. Leg. 17415, año 1476, fol. 118v.

138 Boffey, Julia. "Women authors and women's literacy in fourteenth and fifteenth century England». En Meale, Carol M. (ed.). Women and Literature in Britain, 1150-1550. Cambrige: Cambridge University Press, 1993, pp. 159-182.

139 Dronke, Peter. Women writers of the Middle Ages: a critical study of texts from Perpetua ( $†$ 203) to Marguerite Porete († 1310). Cambridge: Cambridge University Press, 1984, p. X. 
también afectaba a los maestros de primeras letras, cuyos sueldos y tiempo de empleo eran estipulados contrato a contrato siendo de una variedad extraordinaria. En todos los casos el aprendizaje estuvo basado en una cultura escrita que, como hemos comprobado, se hacía cada vez más presente en la sociedad. Conforme los siglos medievales tocaban a su fin, el uso de libros en la vida cotidiana -tanto de las clases nobles como de las populares- se iba haciendo cada vez más frecuente y comenzaban a aparecer las primeras bibliotecas, ligadas a las familias de la nobleza y a la Iglesia.

En el último apartado hemos abordado un tema de difícil estudio debido a la falta de evidencias documentales, la mujer y la cultura. Especialmente hemos podido analizar la vinculación de la mujer con el libro, en su dimensión de lectoras o de difusoras de los instrumentos de cultura. En este aspecto el protagonismo corresponde a las mujeres pertenecientes a lo que en otros trabajos hemos definido como las mujeres religiosas laicas, especialmente los grupos de terceras y emparedadas. Apenas existen evidencias de la formación femenina y de su asistencia a centros de formación. En cualquier caso, estamos convencidos de que el número de mujeres competentes en la lectura y la escritura era mucho mayor que el que revelan los distintos conjuntos documentales. Sin lugar a duda, la participación de la mujer en los resortes articuladores de la economía de las ciudades a la que pertenecían, tal como se ha demostrado en numerosos trabajos, requería de ella unos conocimientos en escritura y lectura, así como en otras prácticas vinculadas a estas competencias.

Durante el siglo Xvi todos los aspectos aquí tratados, enseñanza, libros y agentes femeninos vinculados a la cultura en su más amplio sentido, llegaron a alcanzar unos niveles de desarrollo extraordinarios. Diversos trabajos así lo evidencian. Pero es mucho lo que aún queda por investigar y estudiar. En futuras publicaciones confiamos en arrojar luz sobre el desarrollo cultural andaluz en sus distintas vertientes.

\section{REFERENCIAS BIBLIOGRÁFICAS}

Aliaga Asensio, Pedro. «La Orden de la Santísima Trinidad en Sevilla». En Barrero González, Enrique y Martínez Carretero, Ismael (coords.). Órdenes y congregaciones religiosas en Sevilla. Sevilla: Ateneo de Sevilla, 2008, pp. 273-290.

Álvarez Márquez, María del Carmen. "La biblioteca de la catedral Hispalense en el siglo XV». Archivo Hispalense, 1987, vol. 70, n. ${ }^{\circ}$ 213, pp. 3-68.

Álvarez Márquez, María del Carmen. «Los artesanos del libro en la catedral hispalense durante el siglo Xv». Archivo Hispalense, 1987, vol. 70, n. ${ }^{\circ} 215$, pp. 3-36.

Barron, Caroline M. «The Education and Training of Girls in Fifteenth Century London». Courts, Counties and the Capital in the Later Middle Ages. New York: Sutton Publishing Company, 1996, pp. 139-153.

Barttlet, Anne Clark. Male Authors, Female Readers: Representation and Subjectivity in Middle English Devotional Literature. New York: Cornell University Press, 1995.

Beceiro Pita, Isabel y Franco Silva, Alfonso. "Cultura nobiliar y bibliotecas: cinco ejemplos, de las postrimerías del siglo XIV a mediados del XVI». Historia. Instituciones. Documentos, 1985, vol. 12, pp. 277-350.

Beltrán de Heredia, Vicente. Bulario de la Universidad de Salamanca. Salamanca: Universidad de Salamanca, 1966, vol. I. 
EL ACCESO A LA CULTURA Y LA FORMACIÓN INTELECTUAL EN ANDALUCÍA DURANTE LA BAJA EDAD MEDIA

SILVIA MARÍA PÉREZ GONZÁLEZ Y JUAN CARLOS ARBOLEDA GOLDARACENA

Boffey, Julia. «Women authors and women's literacy in fourteenth and fifteenth century England». En Meale, Carol M. (ed.). Women and Literature in Britain, 1150-1550. Cambrige: Cambridge University Press, 1993, pp. 159-182.

Cabrera Muñoz, Emilio. «La fortuna de una familia noble castellana, a través de un inventario de mediados del siglo XV». Historia. Instituciones. Documentos, 1975, vol. 2, pp. 9-42.

Cabrera SÁnchez, Margarita. «El papel de los universitarios en la Córdoba del siglo xV». En Reglero de la Fuente, Carlos M. (coord.). Poder y sociedad en la Baja Edad Media hispánica. Estudios en homenaje al profesor Luis Vicente Díaz Martín. Valladolid: Universidad de Valladolid, 2002, pp. 333-356.

Cabrera SÁnchez, Margarita. «La nobleza andaluza de finales de la Edad Media: los Guzmanes de Córdoba». Historia. Instituciones. Documentos, 2006, vol. 33, pp. 9-48.

Cabrera SÁnchez, Margarita. «Médicos, cirujanos y curanderos en Córdoba durante la segunda mitad del siglo Xv». Anuario de Estudios Medievales, 1996, vol. 26, n. ${ }^{\circ}$ 1, pp. 329-364.

Carriazo, Juan de Mata. Hechos del condestable Miguel Lucas de Iranzo. Madrid: Marcial Pons, 2009.

Castillo Utrilla, María José del. El convento de San Francisco, Casa Grande de Sevilla. Sevilla: Diputación de Sevilla, 1988.

Caunedo del Potro, Betsabé y Córdoba de la Llave, Rafael. «Oficios urbanos y desarrollo de la ciencia y la técnica en la Baja Edad Media: la Corona de Castilla». Norba. Revista de Historia, 2004, vol. 14, pp. 41-68.

Chinca, Mark y Young, Christopher. Orality and literacy in the Middle Ages. Turnhout: Brepols, 2005.

Collantes de Terán, Francisco. Inventario de los Papeles del Mayordomazgo del siglo XV. Sevilla: Ayuntamiento de Sevilla, 1971.

Cuadra García, Cristina; Graña Cid, María del Mar; Muñoz Fernández, Ángela y Segura Graíño, Cristina. «Notas a la educación de las mujeres en la Edad Media». En Graña Cid, María del Mar (coord.). Las sabias mujeres: educación, saber y autoría (siglos III-XVII). Madrid: Asociación Cultural Al-Mudayna, 1994, p. 33-50.

DRONKE, Peter. Women writers of the Middle Ages: a critical study of texts from Perpetua († 203) to Marguerite Porete († 1310). Cambridge: Cambridge University Press, 1984.

Escobar Camacho, José Manuel. «La educación en Córdoba durante la Baja Edad Media: La enseñanza primaria». Incabo, 1985, vol. 5, p. 40.

García García, Antonio. "La enseñanza reglada del Derecho durante la Baja Edad Media». Ínsula. Revista de Letras y Ciencias Humanas, 2003, n. ${ }^{\circ}$ 675, pp. 12-14.

García Herrero, Carmen. Las mujeres en Zaragoza en el siglo XV. 2. a ed. 2 vols. Zaragoza: Prensas Universitarias de Zaragoza, 2006.

García PARdo, Manuela. «La cultura clerical en el obispado de Jaén en la Baja Edad Media». Hispania Sacra, 1999, vol. 51, n. ${ }^{\circ}$ 104, pp. 703-716.

Garriga Acosta, Carlos Antonio. «La Real Audiencia y Chancillería de Valladolid». En Payo Hernanz, René Jesús y Sánchez Domingo, Rafael (coords.). El Régimen de justicia en Castilla y León: De Real Chancillería a Tribunal Superior. Burgos: Tribunal Superior de Justicia de Castilla y León, Junta de Castilla y León, 2014, pp. 13-98.

GellRich, Jesse M. The idea of the book in the Middle Ages: language, theory, mythology and fiction. New York: Cornell University Press, 1987.

Gimeno Blay, Francisco M. «Aprender a escribir en la Península Ibérica: de la Edad Media al Renacimiento». En Petrucci, Armando y Gimeno Blay, Francisco M. (eds.). Escribir y leer en Occidente. Valencia: Universidad de Valencia, 1995, pp. 125-144. 
Graña Cid, María del Mar. "¿Leer con el alma y escribir con el cuerpo? Reflexiones sobre mujeres y cultura escrita». En Castillo Gómez, Antonio (coord.). Historia de la cultura escrita. Del Próximo Oriente Antiguo a la sociedad informatizada. Gijón: Trea, 2002, pp. 385-452.

Graña Cid, María del Mar. «Beatas dominicas y frailes predicadores. Un modelo religioso bajomedieval de relación entre los sexos (Córdoba, 1487-1550)». Archivo Dominicano, 2011, vol. 32, pp. 219-246.

Graña Cid, María del Mar. «Beatas y comunidad cívica. Algunas claves interpretativas de la espiritualidad femenina urbana bajomedieval (Córdoba siglos XIV-Xv)». Anuario de Estudios Medievales, 2012, vol. 42, n. ${ }^{\circ}$ 2, pp. 697-725.

GraÑa Cid, María del Mar. "El Císter femenino bajomedieval: contenidos carismáticos y funcionalidades políticas (Córdoba, 1260-1510)». Cistercium, 2010, vol. 254, pp. 225-256.

Green, Dennis Howard. Medieval listening and Reading. Cambridge: Cambridge University Press, 1994.

Green, Dennis Howard. Women readers in the Middle Ages. Cambridge: Cambridge University Press, 2007.

Hazañas y La Rúa, Joaquín. Maese Rodrigo, 1444-1509. Sevilla: Imprenta de Izquierdo, 1909.

Huerga, Álvaro. Los dominicos en Andalucía. Sevilla: Convento de Santo Tomás de Aquino, 1992.

Ladero Quesada, Miguel Ángel. Historia de Sevilla. La ciudad medieval. Sevilla: Universidad de Sevilla, 1976.

Larios Ramos, Antonio. «Los dominicos y la Inquisición en Sevilla durante la Modernidad». Revista de Humanidades (Centro Asociado de la UNED de Sevilla), 2016, 27. Disponible en: http://www.revistadehumanidades.com/articulos/111-los-dominicos-y-la-inquisicion-ensevilla-durante-la-modernidad

Le Goff, Jacques. Los intelectuales en la Edad Media. Barcelona: Gedisa, 2009.

López Piñero, José María. «El renacimiento en las ciencias». En Menéndez Pidal, Ramón. Historia de España. Tomo XXI. Madrid: Espasa, 1999, p. 314.

Medianero Hernández, José María. El Convento "Casa Grande» de San Francisco de Sevilla y su repercusión en el ambiente cultural y artístico bajomedieval de la ciudad. Sevilla: Cajasur, 1997.

Miura Andrades, José María. Frailes, monjas y conventos. Las órdenes mendicantes y la sociedad sevillana bajomedieval. Sevilla: Diputación de Sevilla, 1998.

Morales Padrón, Francisco. Historia de Sevilla. La ciudad del Quinientos. Sevilla: Universidad de Sevilla, 1977.

Morgado, Alonso de. Historia de Sevilla. Sevilla: Ayuntamiento de Sevilla, 2017, pp. 129-131.

Parejo Delgado, María Josefa. «El Colegio de los Niños de la Doctrina Cristiana y otras instituciones docentes en Úbeda en el siglo XvI». Hespérides. Anuario de Investigaciones, 1994, vol. 2, pp. 75-90.

Pérez González, Silvia María. «Las mujeres de la muy noble y muy leal ciudad de Jerez de la Frontera. Siglos xiv-Xvi». En SÁnchez Herrero, José y González Jiménez, Manuel (dirs.). 750 aniversario de la incorporación de Jerez a la Corona de Castilla: 1264-2014. Jerez de la Frontera: Ayuntamiento, 2014, pp. 287-305.

Quintanilla Raso, María Concepción. «La biblioteca del marqués de Priego (1518)». En la España Medieval, 1980, vol. 1, pp. 347-383.

Rojas Vaca, María Dolores. Un registro notarial de Jerez de la Frontera (Lope Martínez, 1392). Madrid: Fundación Matritense del Notariado, 1998.

Rubio, Germán. La custodia franciscana de Sevilla. Ensayo histórico sobre sus origenes, progresos y vicisitudes (1220-1499). Sevilla: San Antonio, 1952.

Rubio Merino, Pedro. «Las constituciones del Hospital del Cardenal de Sevilla». Memoria Ecclesiae, 1997, vol. 10, pp. 349-375. 
EL ACCESO A LA CULTURA Y LA FORMACIÓN INTELECTUAL EN ANDALUCÍA DURANTE LA BAJA EDAD MEDIA

SILVIA MARÍA PÉREZ GONZÁLEZ Y JUAN CARLOS ARBOLEDA GOLDARACENA

Rubio Merino, Pedro. Archivo de la Santa Metropolitana y Patriarcal Iglesia catedral de Sevilla. Inventario general. Madrid: Fundación Ramón Areces, 1987.

Sánchez Herrero, José. «Centros de enseñanza y estudiantes de Sevilla durante los siglos xiI al XV». En la España Medieval, 1984, vol. 4, pp. 875-898.

Sánchez Herrero, José. «Convento de San Pablo el Real de Sevilla». En Peñalver Gómez, Eduardo (coord.). Fondos y procedencia: Bibliotecas en la Biblioteca de la Universidad de Sevilla. Sevilla: Universidad de Sevilla, 2013, pp. 126-129.

SÁnChez HerRero, José. «Entre el creer y el saber. Autores de Andalucía de los siglos XIV y XV». En Malpica, Antonio et ál. (coords.). Historia de Andalucia, VII Coloquio. Granada: Universidad de Granada, 2009, pp. 147-178.

Sánchez Herrero, José, «Las bibliotecas del Colegio de Santo Tomás de Aquino y del Convento de San Pablo de la orden dominica en la ciudad de Sevilla». En Córdoba de la Llave, Ricardo et ál. (coords.). Estudios en homenaje al profesor Emilio Cabrera. Córdoba: Universidad de Córdoba, 2015, pp. 545-572.

Sánchez Herrero, José. De las primeras letras a la Universidad en la Sevilla de finales del siglo XV. Sevilla: Servicio de Publicaciones de la Universidad de Sevilla, 2010.

Sánchez Herrero, José y Montes Romero-Camacho, Isabel. "Los colegiales sevillanos del Colegio Español de san Clemente de Bolonia (1368-1600)». En Estudio sobre los orígenes de las Universidades españolas. Homenaje de la universidad de Valladolid a la de Bolonia en su IX Centenario. Valladolid: Universidad de Valladolid, 1988, pp. 135-204.

Sánchez Herrero, José y Pérez González, Silvia María. «Aprender a leer y escribir. Libros y libreros en la Sevilla del último cuarto del siglo XV». Edad Media. Revista de Historia, 1998, vol. 1, pp. 47-90.

Sánchez Herrero, José y Pérez González, Silvia María. «Las gentes del saber o del libro en Sevilla entre 1478 y 1510». En Andalucia medieval: actas del III Congreso de Historia de Andalucía. Córdoba: Cajasur, 2003, vol. 6, pp. 453-469.

Sancho de Sopranis, Hipólito. «La Orden de Sancti Spiritus en el Arzobispado hispalense (1500-1600)». Archivo Hispalense, 1961, vol. 35, n. ${ }^{\circ} 110$, pp. 233-260.

Verger, Jacques. Gentes del saber en la Europa de finales de la Edad Media. Madrid: Editorial Complutense, 1999, p. 229. 
